\title{
Introduction. Challenges in long-term care in Europe
}

\author{
Milena Pavlova ${ }^{1}$ (https:/orcid.orgy0000-0002-6082-8446

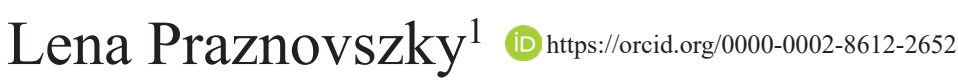

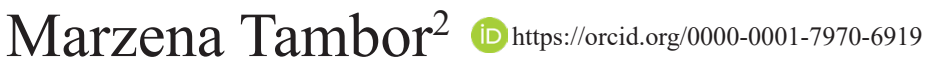

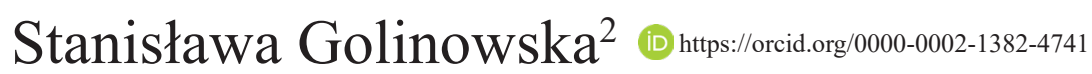 \\ Wim Groot ${ }^{1}$ (https:/orcid.orgy000-0003-1035-5916
}
${ }^{1}$ Department of Health Services Research, CAPHRI, Faculty of Health, Medicine and Life Sciences, Maastricht University, Maastricht, the Netherlands
2 Department of Health Economics and Social Security, Institute of Public Health, Faculty of Health Sciences, Jagiel- lonian University Collegium Medicum, Cracow, Poland

Address for correspondence: Milena Pavlova, Department of Health Services Research, Faculty of Health, Medicine and Life Sciences, Maastricht University, PO Box 616, 6200 MD Maastricht, the Netherlands, +31 433881705 , m.pavlova@maastrichtuniversity.nl

\section{Key worls: ageing, long-term care, Europe \\ Stowa kluczowe: starzenie, opieka diugoterminowa, Europa}

\section{Acknowledgements}

Milena Pavlova is the recipient of an AXA Award of the AXA Research Fund, Project "EuroLTCS Project - Innovative Mechanisms for Sustainable Long-Term Care Systems in Europe". The content of this publication represents the views of the authors and it is their sole responsibility; it can in no way be taken to reflect the views of the AXA Research Fund.

Ministerstwo Nauki i Szkolnictwa Wyższego
Przygotowanie do wydania elektronicznego finansowane w ramach umowy 637/P-DUN/2019 ze środków Ministerstwa Nauki i Szkolnictwa Wyższego przeznaczonych na działalność upowszechniającą naukę.

\section{Ageing and care provision in Europe}

European societies are ageing and the share of older persons is continuously increasing across the region. In 1950, only $12 \%$ of the European population was over 65 years old. At present, this share is already doubled and the estimations suggest that it will be over $36 \%$ in 2050 [1]. The ageing phenomenon is caused by the decreased fertility and increased life expectancy. While in the past, a woman in Europe had on average more than 2 children, since 2000, the fertility rate has fallen below that threshold. Next to that, European citizens live longer, 75 years on average at present compared to 66 years on average in the 1950's [1].
Prolonged human life is a symbol of wealth and prosperity within the European societies but combined with the low fertility rate, it also creates challenges. Most importantly, the group of working people who can provide care to the older persons is shrinking while the group of older persons is becoming larger. Moreover, the increase of longevity is accompanied with a decreasing proportion of years spent independently. Women are particularly affected since most of their years in old age are spent in dependency [2]. The imbalance between the demand and supply is expected to lead to shortages in care providers, a trend already experienced by countries with fast ageing population. 
The increased demand for care will require not only more care providers but also more financial resources. In 2014, the public spending on long-term care in the OECD countries was $1.4 \%$ of GDP but projections suggest that this share will substantially increase till 2050 [3]. There are however substantial differences across the European countries. The highest public spending on long-term care is observed in the Netherlands and Scandinavian countries (3-4\% of GDP) and lowest in countries of Central and Eastern Europe, e.g. less than half percent in Poland, Hungary, Estonia and Latvia [3].

This difference is not surprising given the difference in the long-term care systems in Europe and their historical development. While the Netherlands and Scandinavian countries have well developed systems of care for older persons, which offer a broad range of services, in Central and Eastern European countries, these systems are underdeveloped. The expansion and improvement of medical care provision in these countries during the communist period was not coupled with the same developments in long-term care (LTC). The care for elderly is still largely seen as the responsibility of the family.

\section{Dilemmas for LTC policy in Europe}

The increased involvement of women in the labor market, reduced family size and increased pension age across Europe suggest that there will also be fewer family members available to provide informal care to the older persons. Countries are implementing various strategies to encourage the informal care provision because it is expected to be more cost-effective from a societal point of view [4]. But who controls the quality of informal care and how do we know that the most adequate care is provided? Clearly, informal care will play an important role in Europe also in future but this will not reduce the governments' responsibilities. The governments will have the obligation to monitor the informal care provision and assure its quality. The establishment of quality monitoring mechanisms in informal care, is a challenge in itself.

In addition to the double ageing problem in Europe (declining birth rates coupled with increasing life expectancy) and the changing labor market (more working women and higher pension age), there are several other social trends that question the sustainability of long-term care provision in Europe. Importantly, older persons have now better access to information, which increases their expectations for care and creates demand for more, new and more expensive services, and thus more resources [4]. At the same time, the public resources that can be spent on long-term care are scarce, meaning that they could have a better use within the society. New education or environmental programs that benefit the society at large and not just the group of elderly persons, are some typical examples. Should the European society be spending more on long-term care to meet the increasing demands or should they introduce measure to contain the public spending on this sector?
So far, European countries have answered differently to this question by creating a variety of long-term care systems across the continent. It is however clear that the government support for the extensive long-term care structures established in Western European countries, will be difficult to sustain. For Eastern European countries, there is another policy dilemma because the informal provision takes a considerable toll on family members while resources for creating long-term care institutions are hardly available. Thus, new forms of long-term care financing and provision are needed in both parts of Europe.

It is unclear whether the European societies will choose similar paths and whether the future long-term care reforms will result in more convergent or more divergent systems. Certainly, there will be no unique solution in terms of policy design and implementation given the diversities among the countries in terms of health and care systems, country-specific regulations, workforce problems and fiscal capacities, as well as distinctive social values and culture. Different countries might respond differently to questions on who should be responsible for the care provision (the state, communities or families), and how the long-term care system should be financed and governed to assure its sustainability alongside the equity in access and social cohesion.

Several dimensions could be distinguished with regard to the future evolvement of the LTC systems. They relate to LTC principles, governance, financing, service delivery, management, workforce, information systems and technology $[5,6]$.

\section{ITC guiding principles}

LTC guiding principles regard care for elderly persons from a normative perspective including questions of government legitimacy and accountability [7-9]. The increased role of government in organizing and providing LTC is a comparably new phenomenon, preceded by long traditions of elderly care as belonging to the private sphere [10]. In modern democracies, national welfare policies build on an implicit contract between citizen and government, where the former contributes financially to the realization of national welfare, and the latter carries responsibility for adequate allocation of resources and protection from existential risks, such as illness and poverty [10]. What constitutes an adequate and desirable allocation, may differ between countries and is shaped by a multitude of traditional and cultural factors [11, 12]. Furthermore, national governments carry the responsibility to ensure adequate quantity and quality of care, by monitoring and reacting to changes in demand for care.

Another important aspect of LTC guiding principles, is the perception and framing of old age and ageing. While the notion of active and healthy ageing is already deeply embedded in national policies and public discourse [13], its critics emphasize the pitfall of limiting individuality and diversity, when promoting a dogmatic image of life at old age $[14,15]$. 


\section{ITC governance}

LTC governance regards (power-) relationships, networks and dynamics in the organization of LTC for the elderly persons. It comprises all connections between actors involved in the process of drafting, shaping, implementing and realizing such care $[4,5,16]$. Schemes or levels of governance hereby include laws and policies, which shape the direction of LTC and institutional infrastructures, and are the basis of allocation, regulation and oversight [17]. Care legislation may for example address the scope of and entitlement to public care services [11].

Across Europe, countries differ in their degree of shifting LTC responsibilities from national government to local authorities, and in their positioning of LTC between social and health care [4, 18]. Besides, recent trends towards enhancing public-private partnership in both funding and delivery of care, and increased regulation of care through market forces create new, more diverse LTC landscapes [17, 19-23].

\section{LIC financing}

LTC financing covers the LTC financial planning, savings and investments. First, LTC systems may be categorized by the way how future (financial) burden of care services is planned for, as through extrapolation of population risk and need for care and monitoring of e.g. demographic or economic indicators [4]. European countries differ, in either assuming a proactive or reactive role in funding LTC [24].

Second, sources of LTC funding can be assessed, which are country specific and may be organized via tax levy or insurance schemes and often include user copayments. Generally, a distinction can be made between public funding and private funding, the latter regarding out-of-pocket spending from users or their relatives [4, $20,25]$.

A third aspect of LTC financing refers to the mechanisms of provider payment, which as in health care, may be organized via fixed budgets, quality or quantity related remuneration [4]. Besides, there is a concern for economic loss faced by informal care givers and possible ways of valorizing such care commitment. Informal care givers sacrifice personal time which possibly could be spent in paid work, moreover the productivity of unpaid care work was found to have substantial economic value in the EU and abroad [4, 26, 27].

\section{LIC management}

The focus of LTC management is narrowed down to quality improvement in two areas: direct care outcomes for care recipients and organizational structures, as for example between different LTC actors. The term direct recipient outcomes, entails circumstances directly experienced by recipients of care. It is very closely linked to notions of quality of life, well-being, good mental and physical health, as well as life expectancy $[28,29]$. A central issue for LTC management is thereby the quality of care that dependent persons receive, not only in institutional settings, but also in their own home, when they are cared for informally [30]. Substantial for the assessment of care quality, is the development of checks and indicators as tools for measurement [31,32].

Regarding quality improvement in organizational structures, key challenges of LTC management pointed out by experts, are (lack of) integration and cooperation between involved parties, as well as the need for strategies to make LTC services more adequate and (cost-)efficient $[4,5,33,34]$. The breadth of relationships and interactions characteristic for LTC, may be compared to the payer-provider-recipient network as described for health care [35], therefore similar in complexity and interwovenness. Especially the issue of LTC critical location between health services and social services necessitates clear and distinct LTC solutions $[17,36]$.

\section{LIC service delivery}

Service delivery in LTC is related to services delivered to individuals and their families. The detection of care needs and eligibility assessment for available services marks hereby the starting point. Efficient allocation of care within the national LTC schemes, is not only a matter of doing justice to the individual's needs for care, but is also vital in the light of scarce financial, human and time resources.

Once the eligibility for public services is established, recipients are offered various (non-)cash benefits, such as direct service delivery, by a professional at the recipient's home or in residential settings, or monetary care allowances $[4,10,11]$. To ensure accessibility of care, continuous and well-coordinated infrastructures of provision need to be in place. Settings of LTC provision vary across countries, especially regarding national tendencies towards either informally or formally provided care [17]. Recent literature points to a multitude of approaches, such as home- and community-based services and innovative housing concepts $[37,38]$. Characteristically, LTC service delivery is organized alongside diverse vertical and horizontal levels, connecting national and regional authorities, public and private providers and the health and social care sector in the mutual task to deliver services for elderly persons $[12,17]$.

\section{LTC workforce}

The LTC workforce comprises all individuals, who are organizing or providing LTC services. A broad distinction can be made between individuals delivering care directly, e.g. nurses and social care workers or indirectly e.g. administration employees. Regarding the former group, a further differentiation is made between those, who provide care formally, within registered, paid employment and those, who provide care informally, often without remuneration outside classic employment schemes [39]. Next to traditional patterns of informal care provision within the family, an increasing trend towards informal private care arrangements, employing third persons, of- 
ten labor migrants, in the home environment is apparent across European countries [11].

Furthermore, LTC workforce entails the sum of strategies and policies of workforce planning and capacity building for LTC. The ongoing crisis of workforce scarcity and related quality issues reported from the field of health care, may as well be translated to the field of LTC [40]. A lack of incentives to choose occupation in direct care professions and tendencies of turnover to different job areas by trained staff, are accounted for by various factors. To name a few, physical and emotional strain related to one-to-one care provision and perceived lack of professional recognition and validation, lead to employee dissatisfaction and put quality of care at risk [41, 42]. Besides, there is a need to re-structure professional work fields and to move beyond established job profiles, to adapt better to future LTC needs [43]. The need for sustainable workforce planning, as formulated for the health care sector, is thus similarly relevant to LTC systems [44].

\section{LIC information systems \& technology}

LTC information systems and technology can be considered the motor of progress and development in the field of LTC. They refer to innovations, which guide the LTC systems into more efficient and sustainable pathways. Borrowing from the field of health, e-LTC as extension of e-health comprises the digital data and electronic solutions to support LTC [45]. Driven by the need to manage care efficiently, reliable knowledge must be available for evaluation, e.g. the quality of care and overall system performance. Hereby, the establishment of functional infrastructures to distribute and access such information are a necessary foundation $[4,46]$. Especially for improved organization of LTC, information technology supports ambitions towards increased connectivity and cohesion in care service delivery $[47,48]$.

While data sharing promises better quality of care, notions of data protection and safety are hereby as important for LTC as for the health systems [48, 49]. Partially established mechanisms in health care and LTC include: the handling of care recipient data, such as medical files, and improved dialogue between providers and payers of care services [50]. Furthermore, technical innovations (e.g. in home care) are offering new solutions in the provision of care, responding to scarcity of resources and adding value to the life of care users and their families $[51,52]$.

\section{Policy challenges for LTC in Europe}

Across the European countries, there is demand for more specific legislation to establish clear frameworks for LTC and to improve the overall cooperation between the LTC actors. Legislation is also required to adequately respond to care and social security needs, and to encourage the care delivery by the private sector while implementing standards for care quality.
LTC policies in Europe need to focus on improving user experience related to care quality and accessibility. Future LTC policies in Europe should better acknowledge the interests of users as well as formal and informal caregivers. The burden of care recipients in paying for care should be reduced. While increased financial resources for LTC are needed, this would probably prove difficult given the fiscal pressure on the public budgets. Therefore, there is a need to push forward overall reforms of the LTC financial mechanisms towards improved efficiency and sustainability. An overall increase in formal LTC services is also demanded from the European care policies, especially in the field of home care and outpatient care. In this regard, labor and social policies could also contribute by making formal care jobs more appealing and further endorsing the informal care workforce.

The overall lack of data on LTC systems is another policy challenge. Collection and exchange of information on the structure and functioning of the European LTC systems are vital to facilitate informed decision making and future development of LTC.

In response to the lack of data, the EuroLTCS Project was implemented [53]. The project sheds light on the above policy challenges and provides perspective on future LTC systems. Some of the key project findings are presented in the first three papers included in this special issue. The issue is completed with two other papers related to population ageing, i.e. one presenting sociological perspective on care for older people, and another describing healthy ageing as a strategy to increase healthy life years of older people and thus, to reduce their need for LTC.

\section{References}

1. United Nations, Department of Economic and Social Affairs, Population Division, World Population Ageing 2015 (ST/ESA/SER.A/390), https://www.un.org/en/development/ desa/population/publications/pdf/ageing/WPA2015_Report. pdf (accessed: 10.11.2019).

2. Kingston A., Wohland P., Wittenberg R., Robinson L., Brayne C., Matthews F.E.,..., Arthur A., Is late-life dependency increasing or not? A comparison of the Cognitive Function and Ageing Studies (CFAS), "The Lancet" 2017; 390 (10103): 1676-1684.

3. OECD, Long-term Care, 2019, http://www.oecd.org/els/ health-systems/long-term-care.htm (accessed: 11.12.2019).

4. European Commission, Joint Report on Health Care and Long-Term Care Systems \& Fiscal Sustainability, Vol. 1, European Commission, Brussels 2016.

5. Leichsenring K., Billings J., Nies H., Long-term Care in Europe: Improving Policy and Practice, Palgrave Macmillan, Basingstoke, UK 2013.

6. WHO, Everybody's business-strengthening health systems to improve health outcomes: WHO's framework for action, 2007, https://apps.who.int/iris/bitstream/handle/10665/43918/978 9241596077 eng.pdf (accessed: 10.09.2019).

7. Held D., Models of Democracy, Stanford University Press, Redwood City, CA 2006.

8. Olsen J.P., Democratic order, autonomy and accountability, in: The Routledge Handbook to Accountability and Welfare 
State Reforms in Europe, Routledge, Abingdon, UK 2016: 29-44.

9. Pfau-Effinger B., Culture and welfare state policies: Reflections on a complex interrelation, "Journal of Social Policy" 2005; 34 (1): 3-20.

10. Theobald H., Restructuring elder care systems in Europe: Policy-field, policy transfer and negative integration. Paper presented at the ISA Conference, "Social Policies: Local Experiments, Travelling Ideas", Montreal 2009, https:// www.researchgate.net/profile/Hildegard_Theobald/publica tion/242481850_Restructuring_elder_care_systems_in_Eu rope_Policy-field_policy_transfer_and_negative_integration/links/0c96052e0dd6899aee000000.pdf (accessed: 03.11.2019).

11. Da Roit B., Le Bihan B., Similar and yet so different: cashfor-care in six European countries'long-term care policies, “The Milbank Quarterly" 2010; 88 (3): 286-309.

12. Theobald H., Kern K., The introduction of long-term care policy schemes: Policy development, policy transfer and policy change, "Policy \& Politics" 2011; 39 (3): 325-342.

13. Zaidi A., Gasior K., Zolyomi E., Schmidt A., Rodrigues R., Marin B., Measuring active and healthy ageing in Europe, "Journal of European Social Policy" 2017; 27 (2): 138-157.

14. Boudiny K., Mortelmans D., A critical perspective: Towards a broader understanding of ' active ageing', "E-journal of Applied Psychology" 2011; 7 (1): 8-14.

15. Lassen A.J., Moreira T., Unmaking old age: Political and cognitive formats of active ageing, "Journal of Aging Studies" 2014; 30: 33-46.

16. Vabo S.I., Actors and governance arrangements in longterm care for older people, in: Rescaling Social Policies towards Multilevel Governance in Europe, Routledge, Abingdon, UK 2017: 343-363.

17. Österle A., Long-term Care in Central and South-Eastern Europe: Challenges and Perspectives in Addressing a 'New' Social Risk, "Social Policy \& Administration" 2010; 44 (4): 461-480.

18. Riedel M., Kraus M., Mayer S., Organization and supply of long-term care services for the elderly: A bird's-eye view of old and new EU member states, "Social Policy \& Administration" 2016; 50 (7): 824-845.

19. Barlow J., Roehrich J., Wright S., Europe sees mixed results from public-private partnerships for building and managing health care facilities and services, "Health Affairs" 2013; 32 (1): 146-154.

20. Costa-Font J., Courbage C., Long-Term Care Insurance: Partnership or Crowding Out?, in: Financing Long-Term Care in Europe, Palgrave Macmillan, London 2012: 91-100.

21. Deusdad B.A., Pace C., Anttonen A., Facing the challenges in the development of long-term care for older people in Europe in the context of an economic crisis, "Journal of Social Service Research" 2016; 42 (2): 144-150.

22. Harrington C., Jacobsen F.F., Panos J., Pollock A., Sutaria S., Szebehely M., Marketization in long-term care: A crosscountry comparison of large for-profit nursing home chains, "Health Services Insights" 2017; 10: 1178632917710533

23. Pavolini E., Ranci C., Restructuring the welfare state: Reforms in long-term care in Western European countries, "Journal of European Social Policy" 2008; 18 (3): 246-259.
24. Costa-Font J., Courbage C., Swartz K., Financing longterm care: Ex ante, ex post or both?, "Health Economics" 2015; 24: 45-57.

25. Rothgang H., Social insurance for long-term care: An evaluation of the German model, "Social Policy \& Administration" 2010; 44 (4): 436-460.

26. Hassink W.H., Van den Berg B., Time-bound opportunity costs of informal care: consequences for access to professional care, caregiver support, and labour supply estimates, "Social Science \& Medicine" 2011; 73 (10): 1508-1516.

27. Oliva-Moreno J., Peña-Longobardo L.M., Vilaplana-Prieto C., An estimation of the value of informal care provided to dependent people in Spain, "Applied Health Economics and Health Policy” 2015; 13 (2): 223-231.

28. Karimi M., Brazier J., Health, health-related quality of life, and quality of life: What is the difference?, "Pharmacoeconomics" 2016; 34 (7): 645-649.

29. Şahin D.S., Özer Ö., Yanardağ M.Z., Perceived social support, quality of life and satisfaction with life in elderly people, "Educational Gerontology" 2019; 45 (1): 69-77.

30. Coleman E.A., Falling through the cracks: challenges and opportunities for improving transitional care for persons with continuous complex care needs, "Journal of the American Geriatrics Society" 2003; 51 (4): 549-555.

31. Berg K., Mor V., Morris J., Murphy K.M., Moore T., Harris Y., Identification and evaluation of existing nursing homes quality indicators, "Health care Financing Review" 2002; 23 (4): 19

32. Greve B., Long-term Care for the Elderly in Europe: Development and Prospects, Routledge, Abingdon, UK 2016.

33. Kim E.-Y., Yang B.-M., Cost-effectiveness of long-term care services in South Korea, "Archives of Gerontology and Geriatrics" 2005; 40 (1): 73-83.

34. Lau J.Y.C., Wong E.L.Y., Chung R.Y., Law S.C., Threapleton D., Kiang N.,..., Yeoh E.K., Collaborate across silos: Perceived barriers to integration of care for the elderly from the perspectives of service providers, "The International Journal of Health Planning and Management" 2018; 33 (3): e768-e780.

35. Busse R., Competition in healthcare - a health systems perspective, "Zeitschrift für Evidenz, Fortbildung und Qualität im Gesundheitswesen" 2009; 103 (10): 608-615.

36. Leichsenring K., Integrated care for older people in Europe - latest trends and perceptions, "International Journal of Integrated Care" 2012; 12.

37. Arentshorst M.E., Kloet R.R., Peine A., Intergenerational Housing: The Case of Humanitas Netherlands, "Journal of Housing For the Elderly" 2019; 33 (3): 244-256.

38. Tinker A., Ginn J., Ribe E., Assisted living platform - The long term care revolution: A study of innovatory models to support older people with disabilities in the Netherlands, King's College London, London 2013.

39. Fujisawa R., Colombo F., The long-term care workforce: overview and strategies to adapt supply to a growing demand, 2009, https://www.oecd-ilibrary.org/social-issues-migration-health/the-long-term-care-workforce-overview-and -strategies-to-adapt-supply-to-a-growing-demand_2253506 38472? crawler=true (accessed: 10.12.2019).

40. Kuhlmann E., Batenburg R., Groenewegen P.P., Larsen C., Bringing a European perspective to the health human re- 
sources debate: A scoping study, "Health Policy" 2013; 110 (1): 6-13.

41. Aiken L.H., Sloane D.M., Bruyneel L., Van den Heede K., Sermeus W., Consortium R., Nurses' reports of working conditions and hospital quality of care in 12 countries in Europe, "International Journal of Nursing Studies" 2013; 50 (2): 143-153.

42. Hollinger-Smith L., Ortigara A., Changing culture: Creating a long-term impact for a quality long-term care workforce, “Alzheimer's Care Today" 2004; 5 (1): 60-70.

43. Hussein S., Manthorpe J., An international review of the long-term care workforce: Policies and shortages, "Journal of Aging \& Social Policy" 2005; 17 (4): 75-94.

44. Chen L., Evans T., Anand S., Boufford J.I., Brown H., Chowdhury M.,..., Elzinga G., Human resources for health: overcoming the crisis, "The Lancet" 2004; 364 (9449): 1984-1990.

45. Rahmani A.M., Gia T.N., Negash B., Anzanpour A., Azimi I., Jiang M., Liljeberg P., Exploiting smart e-Health gateways at the edge of healthcare Internet-of-Things: A fog computing approach, "Future Generation Computer Systems" 2018; 78: 641-658.

46. Georgiou A., Marks A., Braithwaite J., Westbrook J.I., Gaps, disconnections, and discontinuities - the role of information exchange in the delivery of quality long-term care, "The Gerontologist" 2012; 53 (5): 770-779.
47. Kruse C.S., Mileski M., Alaytsev V., Carol E., Williams A., Adoption factors associated with electronic health record among long-term care facilities: a systematic review, "BMJ Open" 2015; 5(1): e006615.

48. Marcotte L., Kirtane J., Lynn J., McKethan A., Integrating health information technology to achieve seamless care transitions, "Journal of Patient Safety" 2015; 11 (4): 185-190.

49. van der Haak M., Wolff A.C., Brandner R., Drings P., Wannenmacher M., Wetter T., Data security and protection in cross-institutional electronic patient records, "International Journal of Medical Informatics" 2003; 70 (2-3): 117-130.

50. Liu D., Castle N.G., Health information technology in nursing homes, "Journal of Applied Gerontology" 2009; 28 (1): $38-58$.

51. Agree E.M., The potential for technology to enhance independence for those aging with a disability, "Disability and Health Journal" 2014; 7 (1): S33-S39.

52. Barlow J., Singh D., Bayer S., Curry R., A systematic review of the benefits of home telecare for frail elderly people and those with long-term conditions, "Journal of Telemedicine and Telecare" 2007; 13 (4): 172-179.

53. Pavlova M., Innovative Mechanisms for Sustainable LongTerm Care Systems in Europe - EuroLTCS Project, 2016, https://www.axa-research.org/en/project/milena-pavlova (accessed: 10.11.2019). 